\title{
Capital, culture and urbanization - Analysis of culture urbanization based on perspective of Marx and Engels
}

\author{
Xuechang Zhang \\ Marxism School, Sichuan University, Chengdu, Sichuan 610065, China
}

Keywords: Capital, Culture, Urbanization, Marx and Engels, Culture urbanization

\begin{abstract}
The culture urbanization has significance for the development of new urbanization with Chinese characteristics, and we can draw wisdom from interrelated thesis of Marx and Engels on the culture urbanization. In this paper, to explore the cultural town as the core, with Marx and Engels' relevant thesis as the theoretical basis, analyzes the capitalism urbanization logic from capital urbanization to cultural urbanization, explaining the cultural contradictions of culture urbanization during capitalism period and its bridge, focusing on the cultural development issues of urbanization in China, analyzing culture urbanization, strengthening outstanding culture heritage, maintaining city cultural fair and promoting contemporary choice of urban and rural cultural symbiosis.
\end{abstract}

\section{Introduction}

Urbanization is a systematic project, involving various fields of economy, demography and culture. "National new urbanization plan (2014- 2020)" takes "cultural heritage, highlighting characteristics" as the basic principle of promoting urbanization for the first time, which fully reflects the importance and urgency of culture urbanization. Culture urbanization is the extending of economy urbanization in the cultural field, mainly driven by the capital element. From the point of view the history of ideas, Marx and Engels revealed from the capital city of the cultural city of capitalist urbanization logic to clarify the period of capitalist urbanization cultural connotation of cultural contradictions and bridge, to promote Chinese culture and urbanization, ensure the sustainable development of the new town, great value.

\section{Two dimensions of capitalist urbanization: from capital urbanization to culture urbanization}

Capitalist urbanization reflect the requirements of the development of large industry, subject to the development of capital accumulation orientation is essentially a logical expansion of the capital city. Capitalist period, the city "indicates the population, production tools, centralization of capital, enjoy and demand", [1] the process of urbanization is concentrated on those elements of the city. Compared with other historical periods, capital concentration capitalist urbanization personality traits. Accumulation of capital "caused the most rapid concentration of capital." [2], the concentration of capital makes capital as an independent force, laying the foundation for capital expansion. Breaking the cycle of capital expansion simple reproduction of traditional society, to promote the expansion of reproduction characterized by large-scale industrial development. "In the country as a balanced distribution of large industry is to destroy cities and isolated rural conditions," [3] has accelerated the urbanization of the population. Population of the city into the largest industrial development in the city agglomeration and provides ample labor and market, and promote large-scale industrial "put all capital have become the industrial capital" [1] thereby increasing centralization and expansion capital in the city.

Capital city of the urban culture by reshaping, prompting cultural urbanization. Culture urbanization follow the "create a culture capital" logic, through the capital forced "a considerable part of society" and engaged in "more than their immediate essential needs of labor" [4] implementation. On the one hand, capital by hiring cultural producers, in which their employment relationship dominant cultural production behavior. On the other hand, the capital city to promote cultural production and adaptation of capital urbanization. [5]. "The real center of world trade," the cultural 
and "believed to be the center of the world" culture significantly different, which is rooted in the level of capitalist development in the capital city as the representative of the level difference.

Meanwhile, the cultural city of cultural production implies urbanization of the inherent logic of capital can be counterproductive in the capital city of. Marx and Engels pointed out, the bourgeoisie, "the doctors, lawyers, priests, poets and scholars became its paid wage laborers." [1]. Among them, the priests, poets and academics spirit producers of labor and goods and services in the fundamental capital expansion. Their labor and commercialization of some products, to provide space for capital appreciation. Other products will be their ideology, to disengage the spiritual needs of the real proletariat "unreal" form deceive the proletariat, thus inhibiting the proletariat revolt against capitalism for capital appreciation escort. Therefore, an object of cultural production simplified as profit, the process became the bourgeoisie to extract surplus value realization form, its products become vassal capital. With the production of a particular culture and its promotion of standardization and scale, corresponding cultural industries will form. To maximize profits, these cultural industries will have ample free labor to urban agglomeration and markets, so as to provide power in the capital concentration and expansion of the city.

\section{Cultural contradiction of culture urbanization and its bridge}

Culture urbanization is presenting the capitalist mode of production, intrinsic logic of capital expansion. Marx and Engels, capital expansion brought a significant impact on class relations and urban-rural relations. An important manifestation of these effects is the contradiction at the cultural level of the class culture and urban and rural culture. First, class and cultural conflict. On the one hand, many agricultural transfer of population to the cities from the "idiocy of rural life", [1] to get rid of the shackles of traditional culture in rural areas. On the other hand, under the oppression of the proletariat in the capital of extreme poverty, the emergence of cultural malaise, and by the shackles of bourgeois ideology. In this regard, the proletariat can learn from the city's cultural wisdom, conscious form against bourgeois culture. Thus, the proletarian culture and bourgeois culture there is a conflict, the former from the latter's attempt to slavery, and the latter imprison former. Second, the urban and rural cultural contradictions. On the one hand, and cultural development of the city for the countryside provides the opportunity to improve traction rural social productivity and achieve modern transformation of industry, society and culture. On the other hand, rural culture is urban culture shock, "bound by all the traditions and customs, were legal affiliation, family disintegration", [6] which appeared fracture urban and rural cultural development. With the intensification of urban and rural economic antagonism, urban and cultural opposition also further deepened.

To bridge these contradictions, Marx and Engels argued that the proletarian revolution must be carried out to establish the dictatorship of the proletariat, eliminate exploitation and completely eliminate the influence of the capital of culture, the establishment of free people of the Commonwealth, humanity indiscriminately shared cultural resources. And they reveal a number of specific initiatives: First, to strengthen the cultural heritage, maintain cultural nationality. Of course, the cultural heritage does not mean abandoning the new involution, because the city cannot completely abandon the "all in line with the modern and rational health perspective" [7]. Second, the combination of proletarian power. "Metropolitan eliminate the last vestiges of patriarchal relations between workers and employers", [8] the proletariat not only get rid of the shackles of culture, but also to learn scientific knowledge in the city, so they can achieve ideological emancipation, expansion and consolidation of the proletariat joint to better carry out the revolutionary practice. Third, to achieve the integration of urban and rural. Only through the integration of urban and rural, urban and rural areas in order to eliminate the opposition. And, "through the integration of urban and rural areas, so that all members of society to be fully developed." [1] to the common development of urban and rural culture. Of course, the urban-rural integration alone will not realize the need "to produce a highly developed stage." [9] as a precondition. 


\section{Contemporary choice of culture urbanization: inheritance, fairness and symbiosis}

China urbanization has profound historical background; to solve these problems can draw wisdom from Marx and Engels on the urbanization of culture. Before reform and opening, government policy-led process of urbanization, the slow pace of urbanization; after the reform and opening up capital elements become the main driving force behind the rapid development of urbanization. Today, cultural urbanization should continue to play a positive function of capital elements to avoid the negative effects of capital elements, adhere to the people-oriented, in order to meet the purposes and methods of agricultural work to the spiritual and cultural needs of urban and rural cultural heritage development to explore a suitable for China Road urban cultural development.

\section{Cultural inheritance: outstanding culture inheritance of culture urbanization.}

Contemporary, China's urbanization process, there have been some cultural heritage issues. First, the heritage content selection bias. Accompanied by respect for traditional culture, some cities have sided understanding of the cultural heritage of all the reduction of traditional culture, give up the essence, whichever is dross, resulting in reconstruction Pan Jinlian House and other problems. Second, the inheritance carrier is improper. In the land of urbanization in some cities in order to improve short-term economic benefits of the land, some of the historical and cultural values have completely destroyed the old building and built a tower at the site, making the city "With the building, lost culture"; some the city will tear down the reconstruction of old buildings to make them "With the new look, lost the connotation" and become a destructive "cultural heritage."

Urbanization should strengthen cultural connotation construction of urban culture, heritage and Gung continued to promote the fine traditional culture. First, the rational distribution of urbanization and cultural development, the "cultural heritage" concept into urban planning, integration of excellent traditional cultural elements in urban public building design, public cultural facilities construction process. Second, the scientific conservation of cultural heritage, cultural heritage protection and development unify its economic value, the development of cultural heritage-based urban characteristics of cultural tourism industry, cultural heritage reconstruction constraint demolition, destroy cultural heritage so has irreversibly damaging investment behavior, safe tap the economic potential of traditional cultural resources. Third, to fully stimulate the vitality of capital elements, the financial capital, social capital and traditional cultural resources combine to create urban culture brand, promote both economic growth and cultural heritage "Cultural friendly" industries.

\section{Culture fairness: class culture joint development of culture urbanization.}

Capitalist urbanization, capital greedily expansion led to low income proletariat and poor living conditions, restricted to enhance the quality of their culture, hinder the development of proletarian culture. Contemporary urbanization and capitalist urbanization China are essentially different, but there is not a balanced development between the different sectors of culture. On the one hand, urban residential space differentiation leads to cultural space differentiation. With the development of the real estate industry, urban residential space gradually commercialize its configuration mainly consists of market regulation, income determines the level of the public good or bad quality of urban living space. This differentiation determine its differentiation occupants cultural space, living space the quality greatly influence the public to enjoy the quality of cultural services and the environment. On the other hand, consumption of urban culture leads to cultural space differentiation. Higher income spending power of people's culture, the level and quality than the lower income people is high, the former can get costly elegant cultural influence, which is vulnerable to low-cost, vulgar cultural influences. Overall, the differentiation of urban cultural space, not only for personal development conditions of the people is not balanced, and that will be reflected in the level of social relations, cultural differences curing various sectors, increasing urban culture break.

Culture urbanization should focus on the pursuit of cultural fair, even if the public equal access to modern public cultural services, the provision of basic conditions for their culture to enhance the quality, narrow the gap at all levels of urban culture. Culture is not fair to let people's spiritual and cultural needs of homogenization, but the premise of respecting the diversity of their spiritual and cultural needs, to meet their basic spiritual and cultural needs. On the one hand, to meet the basic needs of all citizens living space, cultural space to prevent the consequent differentiation. On the 
basis of the protection of public living space with a certain city on strengthening cultural construction of urban living space, with emphasis on providing quality cultural facilities and services for poor communities living space, protection of the public equal access to opportunities for promotion and cultural qualities. On the other hand, strengthen the modern public cultural service system, to inhibit differentiation of cultural space. Departure from the public cultural consumption, free and open all kinds of urban public cultural service facilities, promote the "high art into low-income groups' activities, providing them with basic cultural consumer goods more free prevent polarization emerging urban cultural space, the maintenance of urban culture Pattern unity.

Cultural symbiosis: interaction between urban and rural culture of culture urbanization.

Under the background of the new urbanization, urban and rural economic development, resident status in the gradual elimination of binary oppositions, but the contradiction is more difficult to bridge the urban and rural culture. In the gap between the urban and rural economic and social development level of larger contemporary, rural culture are often marked "ignorant", "poverty", "old fashioned" and other labels, it has been rejected by some of the city, leading to separation and unbalanced development of urban and rural culture. Meanwhile, the urban culture of its economic strength as backing, through the influence of migrant workers, students and other ways to penetrate the rural countryside, gradually "reform" rural culture, leading to fatigue and convergence of rural cultural development of urban culture, even resulting in the rural culture "Second, unlike" not only lost its original cultural essence, because the limitations of economic conditions differ from urban culture, the emergence of cultural continuity crisis.

Culture urbanization should promote cultural interaction of urban and rural, the city with rural, township and promote the city to promote the development of urban and rural cultural symbiosis. First, the transfer and development of cultural heritage of the city of techniques, methods, experience the countryside, will be integrated into the modern elements of urban culture spread to the countryside, provide a reference for the development of rural culture. Second, some of the rural cultural elements are integrated into urban culture, urban spread in rural intangible cultural heritage and intangible cultural heritage, so that both retain agricultural transfer of population "nostalgia" and in terms of ideology into the city. Third, the combination of Chinese medium and small cities and small towns coordinated development of the characteristics of play industrial driving effect urban agglomerations. Relying on the development of both cities urban agglomerations, so that large urban agglomerations driven culture industry development of small towns and villages; they build in small towns and villages as a link to the coordinated development of urban and rural cultural industry chain, the activation potential of cultural consumption of urban and rural residents. Fourth, the cultural building a new socialist countryside to provide adequate funding, policy and personnel support, the development of basic indicators of rural culture as a measure of the level of urbanization, support rural cultural development and innovation.

\section{References}

[1] Selected works of Max and Angles Vol. 1. Beijing: People's Publishing House, 2012:184, 194,403,405,308-309

[2] The Collected Works of Max and Angles Vol. 3. Beijing: People's Publishing House, 2009:886

[3] The Collected Works of Max and Angles Vol. 9. Beijing: People's Publishing House, 2009:314

[4] The Complete Works of Max and Angles Vol. 32. Beijing: People's Publishing House, 1998:220-221.

[5] The Complete Works of Max and Angles Vol. 36. Beijing: People's Publishing House, 1975:383.

[6] The Complete Works of Max and Angles Vol. 20. Beijing: People's Publishing House, 1971:706.

[7] The Complete Works of Max and Angles Vol. 1. Beijing: People's Publishing House, 1995:436.

[8] The Collected Works of Max and Angles Vol. 1. Beijing: People's Publishing House, 2009:436.

[9] Selected works of Max and Angles Vol. 3. Beijing: People's Publishing House, 2012:814. 